\title{
Pertencimentos sociais e vulnerabilidades em experiências de parto e gestação na prisão
}

\author{
Childbirth and pregnancy in prison: \\ social belonging and vulnerabilities
}

Gabriela Dalenogare (https://orcid.org/0000-0003-0167-7358) ${ }^{1}$

Letícia Becker Vieira (https://orcid.org/0000-0001-5850-7814) ${ }^{2}$

Rosana Maffacciolli (https://orcid.org/0000-0002-5846-6001) ${ }^{1}$

Deise Lisboa Riquinho (https://orcid.org/0000-0002-6604-8985) ${ }^{3}$

Débora Fernandes Coelho (https://orcid.org/0000-0002-4535-2611) ${ }^{3}$

${ }^{1}$ Programa de PósGraduação em Enfermagem,

Universidade Federal do Rio Grande do Sul (UFRGS). R. São Manoel 963, Rio Branco. 9060-110 Porto Alegre RS Brasil. gabrieladalenogare@ gmail.com

${ }^{2}$ Escola de Enfermagem, UFRGS. Porto Alegre RS Brasil.

${ }^{3}$ Faculdade de Enfermagem, Universidade Federal de Ciências da Saúde de Porto Alegre. Porto Alegre RS Brasil.

\begin{abstract}
Pregnancy and childbirth in prison can intensify power relationships and mechanisms that encourage inequality in care provided to women and children, with adverse consequences for the lives of both. This issue gave rise to research to understand women's experiences of pregnancy and childbirth in prison. Method: working from theoretical perspectives that address intersections among race, gender and social class, this qualitative study was conducted by interviewing women who had left a penitentiary in southern Brazil. The participants, mostly young, black women, reported being subjected to situations of violence from the first approach by the police. Once deprived of their freedom, they were subjected to humiliation, deficient access to health, as well as psychological and moral violence. The experience of childbirth was permeated by institutional violence and feelings of loneliness and helplessness. Noncompliance with legal provisions, reproduction of violence in relations with security agents and systematic neglect of social and health needs are additional effects of the gender, race and social class oppressions that affect pregnant women and nursing mothers in prison.

Key words Women, Violence, Prisons, Maternal health
\end{abstract}

Resumo Gestar e parir na prisão pode aprofundar relações de poder e mecanismos promotores de desigualdades na assistência prestada a mulheres e crianças, com consequências negativas na vida de ambos. O tema suscitou uma pesquisa que objetivou compreender as experiências de gestação e parto de mulheres em situação prisional. Método: estudo qualitativo, sob perspectivas teóricas que abordam interseccionalidades entre raça, gênero e classe social. O estudo foi realizado a partir de entrevistas com mulheres egressas de uma penitenciária no sul do Brasil. As participantes, em sua maioria mulheres negras e periféricas, relatam terem sido submetidas a situações de violência desde a primeira abordagem policial. Quando já privadas de liberdade, foram submetidas a deficitário acesso à saúde, além de violência psicológica $e$ moral. A experiência do parto foi permeada por violência institucional e por sentimentos de solidão e desamparo. O descumprimento de previsões legais, a reprodução da violência nas relações com os agentes de segurança e a sistemática negligência às necessidades sociais e de saúde são efeitos adicionais de opressões de gênero, raça e classe social que afetam as mulheres gestantes e parturientes em situação prisional.

Palavras-chave Mulheres, Violência, Prisões, Saúde materna 


\section{Introdução}

O crescimento das taxas de aprisionamento de homens e mulheres é uma tendência mundial. Segundo a International Centre for Prison Studies, organização não governamental que acompanha as cifras de encarceramento em escala mundial, o Brasil ocupa a quarta posição no ranking de população prisional e a primeira colocação, comparado aos demais países da América Latina ${ }^{1}$.

De acordo com as Informações Estatísticas do Sistema Penitenciário Brasileiro (Infopen), a situação das mulheres merece atenção, haja vista que, comparado ao total registrado no início da década de 2000, houve um aumento ao longo dos anos de mais de $600 \%$ nas taxas de aprisionamento feminino, perfazendo uma taxa de ocupação de $118,8 \%$ presas no país ${ }^{2}$.

O aumento da população carcerária no cenário brasileiro passou a ser objeto de atenção prioritária tanto na agenda dos Direitos Humanos como da Saúde Pública. Essa orientação decorre do fato de o Estado brasileiro ser signatário das Regras de Bangkok, aprovadas no ano de 2010 pela Assembleia Geral das Nações Unidas. Tais regras estabelecem o consenso ético-jurídico internacional sobre o tratamento de mulheres em situação de prisão. Representam, assim, uma resposta às condições que ferem a dignidade das mulheres no exercício da maternidade, reafirmando as responsabilidades dos países com a implementação urgente de leis e políticas de promoção dos direitos humanos ${ }^{3}$.

Há consenso de que as consequências do aprisionamento na vida e na saúde das mulheres difere das sofridas por homens na mesma situação, especialmente se elas estiverem vivenciando a gestação. Muitas são responsáveis pela tutela dos filhos e pela manutenção financeira da casa. Em tais situações, seu aprisionamento empobrece ainda mais a família que passa a necessitar, assim, de uma reestruturação $0^{4}$.

Os sentidos envolvidos na prisão de mulheres que vivenciam gestação e parto nesse ambiente e o impacto dessas experiências para a saúde e para as suas vidas e a de seus filhos foi foco de uma pesquisa realizada em uma Penitenciária Feminina de uma capital do Sul do Brasil. A problemática em questão envolveu os mecanismos promotores de desigualdades presentes na assistência prestada a essas mulheres. Uma perspectiva interseccional de gênero foi operacionalizada como categoria analítica, uma vez que as interações interpessoais e institucionais reproduzem formas extremas de opressão e violência radicalizadas nas experiências de mulheres negras ${ }^{5-10}$.
Considerando esses aspectos, a pesquisa teve como objetivo compreender as experiências de gestação e parto de mulheres em situação prisional.

\section{Método}

Foi adotada metodologia qualitativa do tipo descritiva exploratória, com embasamento em perspectivas teóricas que abordam interseccionalidades entre gênero, raça e classe social ${ }^{5-10}$. O cenário do estudo constituiu-se por municípios do estado do Rio Grande do Sul, onde se localizam os domicílios das mulheres egressas do sistema prisional. Os critérios de inclusão estabelecidos para as participantes do estudo foram: mulheres que experienciaram gestação e parto no sistema prisional e que foram mapeadas pela Secretaria de Saúde (SES) de um estado da Região Sul do Brasil. Quaisquer impedimentos por parte de mulheres em receber a visita da pesquisadora para entrevista foram considerados critérios de exclusão.

A coleta de dados foi realizada no segundo semestre de 2018, a partir de entrevistas em profundidade. No período previsto para coleta de dados, 10 mulheres foram localizadas pelo mapeamento da SES. Dessas, foi possível contato telefônico com oito, para convite à participação na pesquisa. Uma delas não aceitou participar, totalizando assim sete entrevistadas. $\mathrm{O}$ instrumento de coleta de dados foi elaborado para captar a caracterização sociodemográfica e a narrativa gerada em torno da seguinte questão: "como foi a sua experiência de gravidez e parto na penitenciária, desde o momento que chegou até a hora do nascimento do bebê?".

A produção de dados foi diretamente atravessada pela inviabilidade de acesso às mulheres dentro da penitenciária, sendo essa problemática resolvida pela estratégia de captação das mulheres egressas do sistema prisional em seus domicílios. Contudo, essa estratégia mostrou-se igualmente complexa, uma vez que são quase inexistentes projetos e serviços de saúde que acompanhem mulheres e crianças na saída do cárcere e que forneçam dados sobre o paradeiro destas. Resolvido $\mathrm{o}$ acesso às participantes, o contato telefônico foi prejudicado em função de mudanças de número após a saída da prisão. Quando a pesquisadora conseguia o contato, tinha de enfrentar as dificuldades de acesso às residências, que estavam localizadas ou em áreas periféricas dominadas pelo tráfico ou em cidades do interior, que exigiram deslocamentos de até cinco horas. Todos os des- 
locamentos foram realizados pela pesquisadora, que levava em mãos os termos de consentimentos, um gravador digital e um telefone celular. A pesquisadora foi bem acolhida por todas as mulheres. As conversas foram exaustivas e chegaram a durar duas horas.

As entrevistas foram integralmente gravadas e transcritas. Os dados coletados foram organizados com auxílio do $\mathrm{NVIVO}^{\circledR} 12$. Adotou-se a análise temática proposta por Minayo ${ }^{11}$ caracterizada por três etapas. O procedimento de tratamento dos dados, seguindo essa técnica ocorreu, primeiramente com a pré-análise do material coletado. Nessa fase, foi realizada a leitura flutuante do conteúdo das entrevistas, o que estabeleceu um primeiro contato com o material, permitindo as primeiras orientações interpretativas. As fases subsequentes, de exploração dos dados e de tratamentos dos resultados, permitiram a captação de núcleos de sentido, o agrupamento por similaridade de ideias e o recorte de respostas representativas para a composição das categorias temáticas ${ }^{11}$.

O estudo foi aprovado pelo Comitê de Ética em Pesquisa da Universidade Federal do Rio Grande do Sul (CAAE: 84643518.0.0000.5347), atendendo aos aspectos contidos na Resolução do Conselho Nacional de Saúde no 466/2012 sobre pesquisa com seres humanos. Utilizou-se o Termo de Consentimento Livre e Esclarecido, sendo garantido o anonimato das participantes, por meio da substituição da identificação das mesmas por nomes de mulheres latino-americanas que marcaram a história recente com suas lutas pelos diretos e pela dignidade das mulheres.

\section{Resultados e discussão}

Inicialmente, o tema da gestação e parto na prisão suscitou obter do campo dos estudos de gênero e saúde ${ }^{10}$ subsídios teóricos para compreender a relação entre agravos à saúde incidentes nas mulheres e condutas de opressão de suas liberdades e de violência de seus corpos. Ao considerar as características sociodemográficas e outras informações acerca do histórico de vida das participantes do estudo (expostas no Quadro 1), fez-se notória a necessidade de buscar ampliar o debate a partir do estudo das interseccionalidades entre raça, gênero e classe social como componentes de vulnerabilização das mulheres em situação prisional.

Detalham-se essas informações com os seguintes dados: duas mulheres encontravam-se em situação de liberdade e cinco em prisão domiciliar - estando duas delas com monitoramento eletrônico (tornozeleiras); cinco possuíam ensino fundamental incompleto, uma ensino médio incompleto e outra, superior incompleto; no que tange à tipificação do crime, cinco foram presas por crimes ligados ao tráfico de drogas e duas por crimes contra a vida; cinco estavam grávidas no momento do aprisionamento e três estavam gestando pela segunda vez em situação de prisão.

O perfil sociodemográfico das participantes da pesquisa condiz com estudos e relatórios ${ }^{2,12}$ sobre as características predominantes das mulheres brasileiras que gestam nas prisões: $70 \%$ declaram-se negras, $56 \%$ são solteiras, $48 \%$ possuem de 1 a 7 anos de estudos e 62\% estão presas em função do envolvimento com o tráfico de drogas. Numa perspectiva interseccional, tal realidade atualiza-nos a respeito da feminização da pobreza, da discriminação racial e de gênero, dos efeitos sociais da criminalização das drogas e sobre o papel do sistema penal em guiar suas práticas pelo controle dos corpos femininos, perpetuando injustiças sociais ${ }^{5}$.

$\mathrm{O}$ enfoque em gênero, como constructo sociológico e como categoria analítica, historicamente impulsionou compreender que, na base das condutas opressoras às mulheres, há um conjunto de normas sociais impelindo-as a adotarem comportamentos compatíveis com o desempenho de certos papeis na sociedade, sem o que, passam a ser alvo de perseguição moral e misoginia ${ }^{13}$. No que tange às mulheres negras, outros referencias apontam para uma prática discursiva comprometida com a visibilização das condições socio-históricas que determinam diferenciais nas desigualdades sociais vivenciadas por elas. Nas origens do racismo americano e brasileiro, por exemplo, o argumento da inferioridade racial serviu de justificativa para a escravidão. $\mathrm{O}$ engendramento desse imaginário foi a tal ponto poderoso que determinou, através dos tempos, a premência da pobreza e das desigualdades e injustiças sociais, institucionais e político-sociais na trajetória de vida desses grupos ${ }^{6,7}$.

As reivindicações por justiça social para as mulheres negras, portanto, perpassam esse histórico, uma vez que para elas as demandas prioritárias de vida envolvem situações de desemprego que as afeta e aos seus companheiros, falta de oportunidades para construírem uma carreira profissional e tratamento injusto de seus filhos ${ }^{6,7}$. Especificamente quanto à saúde, os motivos para se preocuparem envolvem vulnerabilidades que surgem pelo pior acesso e qualidade de atendimento em saúde como consequência do racismo institucional ${ }^{14}$. 


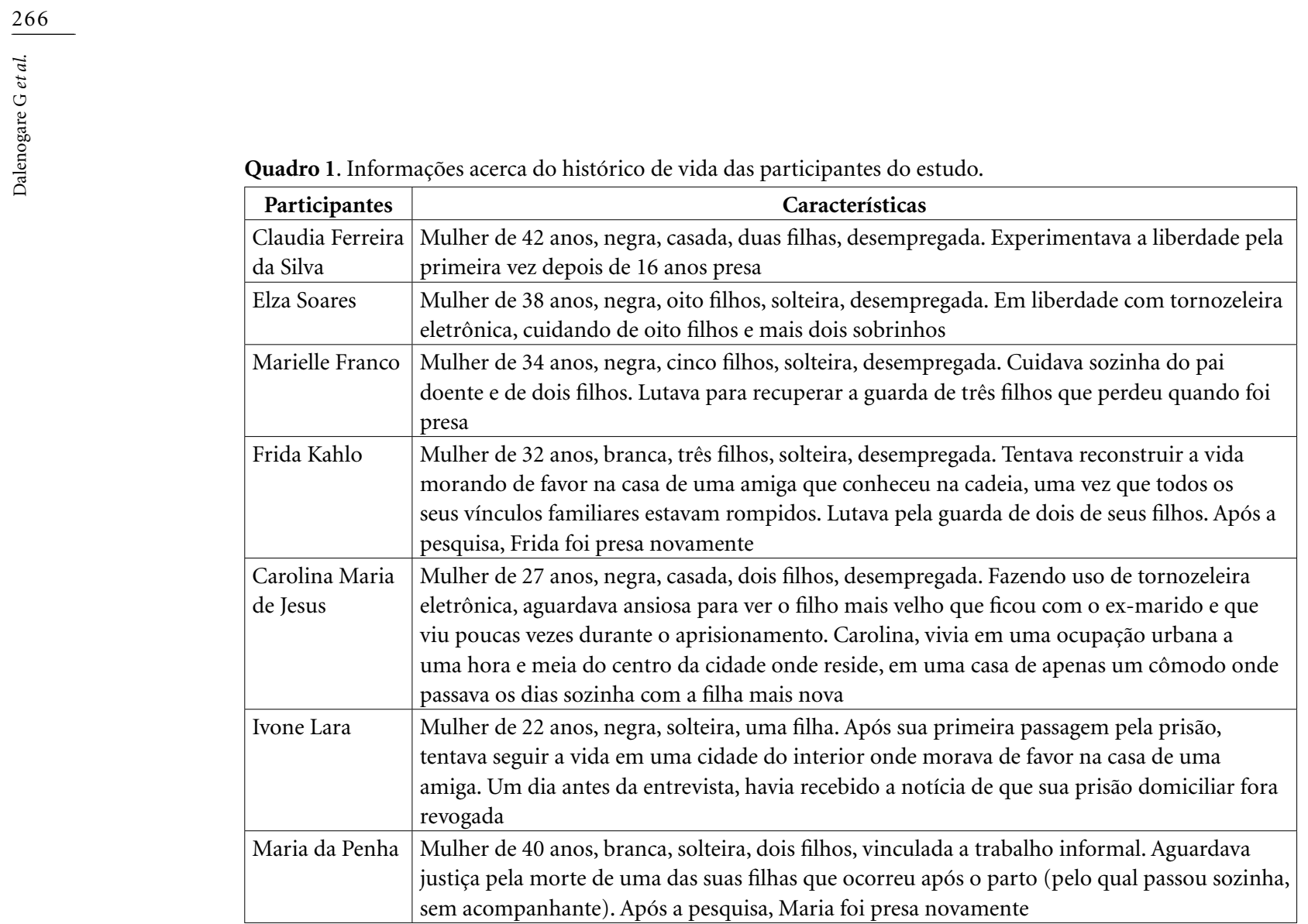

Fonte: Autoras.

Na contemporaneidade, a noção de vulnerabilidade em saúde busca explicitar que o maior ou menor grau de suscetibilidades aos agravos relaciona-se às condições que os sujeitos têm de se proteger, no âmbito do que conseguem fazer por si mesmos e do que os governos ofertam em termos de garantias de direitos sociais ${ }^{15}$. Essa concepção elucidou uma importante questão a respeito dos processos que vulnerabilizam certos grupos desprestigiados em função de serem mulheres, da cor preta de suas peles e de terem uma desprestigiada posição econômica na sociedade. A sobreposição dessas categorias produz sinergia de desigualdades sociais e ampliação das desvantagens desses grupos no cuidado de $\mathrm{si}^{16}$. A presentificação da violência como experiência que corrompe a dignidade, as possibilidades de prosperar na vida e a manutenção da saúde ${ }^{17}$ é uma das resultantes mais expressivas desse processo de rechaço moral e vulnerabilização social.

Três tópicos temáticos, produzidos a partir das especificidades das experiências das participantes da pesquisa, permitiram desvendar a violência como traço flagrante de vulnerabilização baseado no pertencimento social de mulheres periféricas, negras e envolvidas com o crime.

\section{Aprisionamento e a gestação: experiências de violência dentro e fora do cárcere}

Nesse tópico, são descritas a interação inicial das mulheres com os policiais, a chegada na penitenciária e as condições dos alojamentos destinados às mulheres no começo da gestação.

A abordagem policial, ocorrida no momento do aprisionamento - seja na sua residência ou em via pública - constituiu o primeiro momento intenso de violência. Esse momento foi marcado por agressões físicas, juízos de valor e atitudes depreciativas em relação às mulheres. Mesmo ainda estando em condição de suspeitas, elas foram tratadas como culpadas o que, consequentemente, irrompeu atitudes punitivistas de violência frente ao possível delito: "Me levaram para um quarto e me torturaram: me deitaram na cama, com uma toalha no meu rosto e jogaram um galão de água" (relata Ivone Lara). "O policial com uma sacola começou a me sufocar, segurava bem e enrolava pra não entrar o ar. Meu pai disse pro policial: ela está grávida! Ele respondeu: então é agora que ela vai ganhar (ter o bebê)!" (relata Marielle Franco). "Falaram que se eu não colaborasse iam mandar as minhas crianças para o abrigo e chamar 
o Conselho Tutelar, e que perderia as crianças!" (relata Frida Kahlo).

A prisão ampliou as vulnerabilidades observadas no histórico de vida das participantes dessa pesquisa, sendo que esse é, possivelmente, um dos eventos mais críticos nas suas trajetórias de vida. A análise demonstrou que grande parte delas passaram por revitimização, relatando como comuns episódios de ameaças, abusos, violências, experiência de abandono e negligências, no momento da primeira abordagem policial e dentro prisão. Essas situações fragilizaram-nas física, psíquica, social e economicamente, e acabaram por duplamente castigá-las, se considerarmos sua condição como mulheres negras ${ }^{18}$.

Ao examinar especificamente a situação das mulheres participantes deste estudo, revelouse que a violência, expressa em diferentes contextos e formas, foi um fenômeno contundente nas experiências de gestação e parto no sistema prisional - do marco inicial ocorrido no ato da prisão, incluindo meios de tortura como ameaças e sufocamento, até outras formas expressas pela exposição à violência psicológica e negligência.

A chegada à penitenciária é marcada pela necessidade de demonstração/confirmação da gestação, uma vez que isso, na percepção das mulheres, lhes garantiria maior proteção, seja em função dos cuidados à saúde no pré-natal ou frente a possíveis conflitos com mulheres de outras facções ligadas ao crime. Desse modo, na chegada, as mulheres solicitam acesso à Unidade Básica de Saúde Prisional (UBSp) para realizar o teste rápido de gravidez: "Cheguei e fiz o teste de gravidez, viram que eu estava grávida e fui pro salão [local de exclusiva circulação e permanência de gestantes]" (Ivone Lara). "Me mandaram lá pra triagem e expliquei toda gravidade da minha gravidez. Eu tinha todos os meus exames, carteirinha do pré-natal. Ainda bem que estava com a minha bolsa quando eu fui pega" (Frida Kahlo). "Entrei no presídio com medo da facção. Medo de subir para a galeria [setor de comum circulação entre as presas]. No dia do exame, eu pedi pra Deus 'tomara que esteja grávida', assim eu não subo pra galeria” (Marielle Franco). “[...] Falei: eu não posso ficar aqui, estou grávida!" (Elza Soares).

A comprovação da gravidez garante às mulheres o alojamento no salão - um dos locais específicos para gestantes na penitenciária. Embora as que desejam permanecer com seus filhos após o parto sejam encaminhadas para uma penitenciária que possui uma Unidade Materno Infantil (UMI) - que seria um espaço adequado para permanecerem -, as mulheres relatam que esse espaço também não possui infraestrutura. Tal situação as leva a permanecerem mais tempo no salão, lugar descrito como insalubre e inadequado às necessidades mínimas de uma gestante.

No salão, as experiências incluem privação de sono, alimentação precária e medo de adquirir doenças pelas más condições de higiene do espaço. Além disso, a assistência à saúde é insuficiente, uma vez que as entrevistadas relataram dificuldades de acesso a vacinas, exames de ultrassonografia e de sangue e consultas de pré-natal. As mulheres sentiam-se desatendidas em relação a suas necessidades básicas e de saúde: "No salão das gestantes é horrível! Tem oito camas num espaço pequeno. Quando chegava mais, deitava no chão, se amontava ali. Tem só uma janela, não tem ventilação, acordava de manhã e tinha o cheiro de xixi do gato" (Ivone Lara). "Não tem nada ali dentro, fica distante de tudo, um atendimento tem que gritar, pedir socorro" (Claudia Silva Ferreira).

A violência estrutural que se expressa sobre o corpo das mulheres que gestam em situação de prisão ou que permanecem com seus filhos na penitenciária inclui desde necessidades básicas não supridas e más condições de infraestrutura até situações mais insidiosas e cruéis. Essas situações as aniquilam socialmente e diminuem as possibilidades de crescimento e desenvolvimento psicossocial das crianças ${ }^{19}$.

No âmbito das privações, a alimentação foi considerada de má qualidade pelas participantes, coincidindo com o que já se conhece sobre maternidade no cárcere ${ }^{20}$. A alimentação é um direito que não se refere apenas ao ato de se alimentar, mas a adequação em termos de quantidade e qualidade. Outro tipo de privação relatado pelas mulheres relaciona-se às condições de repouso e de sono. Muitas reclamaram que passaram as primeiras semanas de gestação na penitenciária dormindo no chão e enfrentaram a superlotação e a insalubridade das celas.

Diversas formas de humilhação por parte dos agentes de segurança são relatadas pelas mulheres. Houve momentos em que as manifestações depreciativas mostravam-se mais agressivas diante de solicitações para algo de que elas necessitavam. Em outros, notabilizava-se a tentativa de rebaixamento moral apelando-se para estereótipos relacionados a estar na "cadeia" e a uma "gravidez indesejável": "Em vez de perguntar o que estamos querendo elas dizem: 'fica quieta, cala a boca! Ninguém vai te atender agora! Ninguém tá te ouvindo" (Claudia Silva Ferreira). "Quando 
eu chamei me disseram: 'Quantas vezes tu veio pra cadeia? Já te largaram de mão. Nem contamos que tu está grávida. Nem eu quis acreditar que tu está grávida"' (Elza Soares).

A violência psicológica, com ofensas e tentativas de desmoralização relatadas pelas mulheres agravavam o sentimento de solidão, medo e desamparo. O modo peculiar com que se expressavam as hostilidades na prisão e a negligência às necessidades físicas e emocionais das mulheres gestantes é uma situação que remete à análise da misoginia dentro da prisão. Nesse contexto, muitos tipos de violência de gênero existentes no ambiente exterior à prisão são reproduzidos ali, mas de forma ainda mais brutal e mais injusta ${ }^{21}$, uma vez que não há qualquer possibilidade de autodefesa. Também se ressalta que, em alguns casos, os próprios agentes de segurança provocaram as desavenças, seja pela redução do quantitativo de pessoal para o atendimento às demandas, seja pela reprodução de discursos inferiorizantes relacionados às mulheres ${ }^{22}$.

Do aprisionamento à permanência no salão da penitenciária, que corresponde normalmente ao primeiro e segundo trimestres da gestação, as mulheres convivem cotidianamente com a violência. Essa situação ganha outros contornos no decorrer da gestação dentro da prisão, conforme descrito a seguir.

\section{De presa à “mãezinha”}

$O$ ingresso na Unidade Materno Infantil (UMI) passa a influenciar na aquisição de novos atributos às mulheres. Transitam da condição de "presas" à condição de mulher gestante ou de "mãezinhas", adjetivo comumente utilizado pelos agentes e profissionais de saúde neste ambiente.

A nova forma de identificação provoca mudanças na atenção recebida pelas mulheres, especialmente no que se refere à diminuição dos episódios da violência. Neste local, elas passam pelo período da gravidez em que o abdome está mais protuberante, o que sinaliza de forma mais explícita gestação. É nessa circunstância que surge a identidade de "mãezinha". Permanecem sendo chamadas assim enquanto gestantes e após o nascimento de seus filhos(as). Para as mulheres preponderou a noção de que somente na UMI elas acessam alguns serviços e cuidados que anteriormente haviam sido negligenciados: "Na UMI foi que eu comecei ter um pouquinho mais de ajuda, tinha a assistente social, a psicóloga, pois lá na galeria elas não estavam nem aí" (Frida Kahlo). "Eu fui pra UMI e só aí conheci a médica que me atendeu” (Maria da Penha). "Quando fui pra UMI que eu fui melhor tratada” (Carolina Maria de Jesus).

O contexto de violência foi contundente nas experiências vivenciadas pelas mulheres, no entanto, alguns relatos chamaram a atenção para um deslocamento de foco notadamente relacionado à condição da gestação nas mulheres. Muitas delas relataram se sentirem mais respeitadas e bem tratadas na medida em que se tornava aparente seu estado gestacional. Houve, nesse momento, certa atenuação das privações e agressividades que vinham sofrendo, fenômeno provavelmente associado a uma visão que privilegia a proteção da criança em detrimento das necessidades das mulheres ${ }^{21}$.

Pesquisas ${ }^{9,21,23}$ anteriores que identificaram essas mudanças no padrão de cuidado de mulheres gestantes e puérperas ao longo da permanência na prisão apontam que, se por um lado há um acréscimo de apoio dado às elas, por outro, há uma exigência rigorosa de que cumpram adequadamente seu papel de mães. Uma dessas pesquisas demarcou que a vulnerabilidade destas mulheres a sofrimentos psíquicos e morais estava relacionada à pressão sobre elas que se ampliava na interação entre os mecanismos disciplinares característicos do sistema penitenciário e as práticas de controle de si que as mulheres-mães deviam realizar em função do cuidado e proteção dos filhos(as) ${ }^{9}$.

Mesmo na UMI, unidade que tem como finalidade acolher e prestar assistência às gestantes e puérperas com seus filhos/as, as mulheres relataram a limitação do serviço de saúde oferecido. Destacaram o insuficiente número de consultas de pré-natal realizadas, dificuldades de acesso à rede externa de saúde para realização de exames, vacinas e consultas em serviços especializados. Além disso, salientaram os entraves da segurança (falta de efetivo e não garantia de escoltas), que se dá pela questão da logística de deslocamento das mulheres aos serviços de saúde da rede: "A médica me disse que não sabia lidar com gravidez de alto risco, pediu que se possível eles me levarem pra fazer o tratamento na rua, mas demoraram pra me levar, porque a gente dependia muito da escolta, nem sempre tinha" (Frida Kahlo). "Era muito difícil de me chamar para consultas [...] sendo que eu descobri logo no início a gestação de alto risco" (Maria da Penha). "O carro e as guardas pra ir nas consultas nem sempre tinha [...] senão tivesse guarda pra ficar na cadeia a gente não ia na consulta" (Carolina Maria de Jesus). 
Em relação ao parto, a violência se manifestou nas condutas dos agentes de segurança e de saúde, os quais, com atitudes agressivas e hostis, levantaram barreiras para atenção a um parto humanizado, que respeitasse a dignidade das mulheres e das crianças. Revisão da literatura científica identificou que as fragilidades na atenção às mulheres que gestam e têm seus filhos no sistema prisional, além de resultarem no comprometimento da saúde do binômio mãe-filho, elevam os índices de morbimortalidade materna e neonatal ${ }^{19}$.

A vivência no terceiro trimestre da gestação na prisão ocorreu em condições mais favoráveis. A concretização da gestação atribuiu às mulheres a condição de mãe, o que resultou na diminuição da exposição a situações de violência e em melhor assistência às demandas de saúde, embora ainda limitada. As experiências limítrofes em relação à violência voltam a ser suscitadas pelas mulheres ao relatarem o momento do parto em meio à situação prisional.

\section{Parto: violência e solidão}

O trabalho de parto foi percebido como doloroso e angustiante, não apenas pelas características fisiológicas dessa condição, mas também pelo estado degradante da assistência ofertada desde a remoção da unidade prisional até a instituição de saúde. As entrevistadas produziram relatos sobre suas experiências e de outras mulheres com a cumplicidade de quem conviveu com as mesmas hostilidades, privações e negligências.

Na penitenciária, o trabalho de parto tem sua evolução acompanhada pelas profissionais da Unidade Básica de Saúde Prisional, que avaliam o momento em que as mulheres devem ser encaminhadas à maternidade. Durante o período noturno ou em fins de semana, na contramão das prerrogativas profissionais, o acompanhamento e decisão de encaminhamento da mulher à instituição de saúde é realizado pelos agentes de segurança: "Chamei a guarda e fiquei esperando, pois acharam que eu não ia ainda entrar em trabalho de parto. Aí começou a sair muita coisa, começamos a gritar de lá e as guarda vieram e me levaram pro hospital" (Ivone Lara). "Fui no vaso vi que tinha muito sangue, avisei as agentes e elas me levaram" (Frida Kahlo).

O parto foi reconhecido pelas mulheres como um momento de muita angústia e solidão, mesmo entre aquelas que se sentiram cuidadas. Sem a presença de acompanhantes da escolha da mulher e, muitas vezes, sem poder avisá-los sobre a situação, as mesmas são acompanhadas pelas agentes de segurança. Apesar da proibição legal do uso de algemas em trabalho de parto e parto, houve relato desta prática entre as participantes do trajeto da penitenciária até a instituição de saúde: "Ninguém podia ir comigo, não avisaram minha família. Só depois que eu voltei pra cadeia! Me senti muito sozinha! Tinha muito medo porque era um parto bem arriscado" (Frida Kahlo). "Algema, sim! Qualquer coisa que é pra sair do presídio eles botam algema, tanto pra vacina, consulta, parto, algemada!" (Ivone Lara). "Ficou na escolta dois homens [...]. Dormiram comigo lá dentro do hospital! Muito constrangedor, até pra amamentar, ficaram olhando meus peitos" (Carolina Maria de Jesus).

$\mathrm{O}$ tratamento oferecido pela equipe da instituição de saúde é percebido de diferentes formas pelas mulheres. Algumas elogiaram e se sentiam gratas aos profissionais que as acompanharam durante o período de trabalho de parto e internação. Outras relataram ser tratadas com indiferença, negligência e violência. Contudo, mesmo as mulheres que elogiaram o atendimento ofertado mencionaram serem estigmatizadas em algum momento: "No hospital foi incrível! Os médicos sempre me atenderam bem, já tinha feito já o pré-natal lá antes dos outros filhos, mesmo sendo na situação de presa" (Frida Kaho). "O tratamento de uma pessoa presa dentro no hospital é totalmente diferente. Tratam a gente como se fossemos um lixo! Fui maltratada lá dentro!” (Cláudia Silva Ferreira). "Têm alguns que te tratam com bastante indiferença, nem falavam comigo. Porque você está presa é o lixo da sociedade! Todos te veem como uma pessoa ruim" (Ivone Lara).

A questão da violência durante o processo de parto tem sido um tema de crescente interesse, haja vista o número significativo de relatos e denúncias surgidas nos últimos anos, no Brasil ${ }^{23-25}$. A revisão integrativa da literatura apontou que esse contexto abrange as situações expressas em atos negligentes, abusivos, imprudentes, omissos, discriminatórios e desrespeitosos ${ }^{23}$. Esses atos são exercidos, sobretudo, por profissionais de saúde, seja no cenário público ou privado e estão fundados em relações de poder e autoridade sobre o corpo feminino ou sua sexualidade. Convergindo com o perfil das mulheres que gestaram na prisão, destacaram-se as mulheres pobres e negras como as mais afetadas pelo problema. A vulnerabilidade às diferentes formas de violência obstétrica aumentou para o grupo de mulheres pertencente às minorias étnicas, adolescentes, pobres, com baixa instrução escolar, com ne- 
cessidades decorrentes do uso drogas, mulheres vivendo em situação de rua mulheres sem acompanhamento de pré-natal e sem acompanhante no momento do atendimento ${ }^{12}$.

Os depoimentos também revelaram a desatenção às boas práticas relacionadas ao parto, com o uso de medidas intervencionistas para sua celeridade. Dentre essas destacaram-se a ausência de acompanhante, não oferta de analgesia à parturiente ou de métodos não farmacológicos para alívio da dor, não oferta de alimentação durante o trabalho de parto e repetidos exames de toque sem necessidade ou critério técnico que os justificassem ${ }^{26}$ :

Insistiram que eu tivesse parto normal, sendo que minhas gêmeas estavam na mesma placenta e uma estava virada e a outra sentada. No dia que fui pro Centro Obstétrico, viram que não tinha dilatação, enfiaram o dedo no colo do útero pra abrir com o dedo mesmo [...]. Empurraram ela pra dentro da minha barriga de volta e me levaram pra cesárea de urgência! Depois que nasceu eu nem vi ela, fui ver só de tarde! Me deixaram sozinha! A outra nem vi, só depois que morreu! (Maria da Penha).

Cheguei e já começaram a induzir o parto. Eu gritava, gritava! Pedia socorro! Toda hora faziam exame de toque, o médico, o enfermeiro [...] estouraram minha bolsa, o lençol ficou cheio de sangue e eu gritando de dor [...] fecharam a porta e me deixaram só com as guardas no quarto (Claudia Silva Ferreira).

São extremamente dramáticas as cenas descritas e vivenciadas pelas mulheres em suas experiências de parto no contexto prisional. No caso que envolveu a morte de um dos bebês, da gestação gemelar de Maria da Penha, não houve qualquer investigação de imprudência ou negligência dos profissionais e agentes que a atenderam. Esses episódios podem ser considerados mais um indício de que a violência obstétrica culmina em contextos em que a assistência é mais rude e humilhante ao ser prestada a mulheres pobres, negras e em situação de encarceramento ${ }^{25}$.

No debate em torno do encarceramento de mulheres gestantes e parturientes, tem-se avançado no reconhecimento dos fatores que aumentam o risco e a reincidência no envolvimento com o crime, como sexismo, racismo, baixo nível educacional/econômico e antecedentes de trauma e adversidades. Nos depoimentos das mulheres, evidenciam-se modos de interação do setor de saúde com o de segurança pública, que não promovem condições favoráveis à proteção das mesmas, assim expondo a pressão exercida pelos fatores acima mencionados nessas instituições para o desvirtuamento de suas funções quando se trata de mulheres negras. Oportunamente, diante dessas evidências, vale recorrer ao conceito de racismo institucional como

o fracasso das instituições e organizações em prover um serviço profissional e adequado às pessoas em virtude de sua cor, cultura, origem racial ou étnica. Ele se manifesta em normas, práticas e comportamentos discriminatórios adotados no cotidiano do trabalho, os quais são resultantes do preconceito racial, uma atitude que combina estereótipos racistas, falta de atenção e ignorância ${ }^{27}(\mathrm{p} .22)$.

Apesar dos esforços em abarcar práticas mais humanizadas e de superação do racismo institucional, pouco avanço se observa no desmonte de sistemas que contribuem para uma proporção desigual de mulheres negras que vivenciam as experiências degradantes de parto e gestação na prisão $^{26}$. Nesses sistemas, o conjunto de opressões e violências como essas demandas interpretação a partir de uma perspectiva interseccional. Nesse sentido, o conceito de interseccionalidade pressupõe lidar não com grupos distintos de pessoas, mas empreender análises com base na sobreposição de certas características pessoais. Assim, no centro da intersecção entre ser mulher, ser pessoa negra e ser pessoa pobre, encontram-se as mulheres de pele mais escura e as que tendem a ter seus direitos civis e humanos mais desrespeitados ${ }^{8}$.

Acredita-se que considerar a interseccionalidade dos fatores que promovem desigualdades sociais na trajetória de vulnerabilidade das mulheres que vivenciam parto e puerpério nas prisões permite uma melhor instrumentalização para enfrentar a violência que elas vivenciam nesse contexto. As estratégias programáticas que se ocupam da proteção e assistências a essas mulheres e seus filhos/as serão exitosas na medida em que consigam desconstituir as razões morais e o conteúdo estigmatizante que influencia a conduta dos agentes de Estado a respeito desse público e desvele estes mecanismos de reforço das desigualdades de gênero, raça e classe social.

\section{Considerações finais}

As experiências de gestação e parto de mulheres no sistema prisional são permeadas por violências que agravam suas condições sociais e de saúde e, potencialmente, a de seus filhos(as). Muito embora, existam marcos legais que objetivam garantir as condições mínimas para o tratamento de mulheres em situação de prisão, o sistema de segurança parece ser uma malha impermeável 
aos direitos humanos e equidade de gênero. Cabe salientar que há um reconhecimento por parte das mulheres do trabalho e postura positiva de alguns profissionais de segurança e dos trabalhadores de serviços de saúde, o que demonstra que há possibilidades de transformar a prisão a partir de práticas de cuidado que mitiguem as opressões e violências sofridas pelas mulheres.

O desafio colocado com os resultados deste estudo é que não basta identificar a violência sofrida pelas mulheres na prisão durante a gestação, parto e puerpério. É preciso compreender o que sustenta essa estrutura e que mecanismos institucionais devem ser acionados para banir esse fenômeno. Nesse sentido, a prisão é o reflexo de um contexto sociocultural marcado pela interseccionalidade entre racismo, sexismo e desi- gualdades de classe social, processo que amplia, para a população negra, pobre, oriunda de regiões periféricas das cidades e para as mulheres, a exposição à violência, omissão e negligência do Estado.

Salienta-se que o Estado deveria ter papel fundamental na garantia de direitos, uma vez que este tem responsabilidade no fomento e implementação de políticas públicas comprometidas com a justiça e a proteção social. Nesse cenário, destaca-se o papel central dos serviços de saúde e dos trabalhadores do setor no enfrentamento a todos os tipos de violência perpetradas às mulheres, uma vez que configuram um dispositivo disponível dentro das prisões e que pode intervir com práticas de cuidados inclusivas e humanizadas a este segmento.

\section{Colaboradores}

G Dalenogare trabalhou na coleta de dados. G Dalenogare, LB Vieira e R Maffacciolli trabalharam na concepção do estudo; análise e interpretação dos dados; discussão dos resultados. LB Vieira, R Maffacciolli, DL Riquinho e DF Coelho trabalharam na redação e/ou revisão crítica do conteúdo; revisão e aprovação final da versão final.

\section{Financiamento}

Bolsa de Mestrado pela Coordenação de Aperfeiçoamento de Pessoal de Nível Superior (CAPES). 


\section{Referências}

1. Walmsley R. World prison population list. London: Institute for Criminal Policy Research; 2015.

2. Silva MVMT. Relatório temático sobre mulheres privadas de liberdade. Infopen Mulheres. Brasília: Ministério de Justiça e Segurança Pública; 2017.

3. United Nations (UN). United Nations Office on Drugs and Crime. United Nations rules for the treatment of women prisoners and non-custodial measures for women of fenders (The Bangkok Rules). New York: United Nations; 2010.

4. Diuana V, Ventura M, Simas L, Larouzé B, Corrêa M. Women's reproductive rights in the penitentiary system: tensions and challenges in the transformation of reality. Cien Saude Colet 2016; 21(7):2041-2050.

5. Germano IMP, Monteiro RAFG, Liberato MTC. Critical criminology, feminism and intersectionality to approach the rise of female incarceration. Psicol Cien Prof 2018; 38(n. esp. 2):27-43.

6. Hudson-Weems C. Africana womanism: an overview. In: Aldridge DP, Young C. Out of the Revolution: the development of africana studies. Plymouth: Lexington Books; 2000. p. 205-217.

7. Carneiro S. Mulheres em movimento. Estud Av 2003; 17(49):117-133.

8. Carbado DW, Crenshaw KW. An intersectional critique of tiers of scrutiny: beyond "either/or" approaches to equal protection. YLJ 2019; 129(6):19-44.

9. Diuana V, Corrêa MCDV, Ventura M. Women in brazilian prisons: tensions between punitive disciplinary order and maternity prescriptions. Physis Rev Saude Colet 2017; 27(3):727-747.

10. Gomes R, Murta D, Facchini R, Meneghel ST. Gender and sexual rights: their implications on health and healthcare. Cien Saude Colet 2018; 23(6):1997-2006.

11. Minayo MCS, Deslandes SF, Gomes R. Pesquisa social: teoria, método e criatividade. 34a ed. São Paulo: Vozes; 2015.

12. Leal MC. Childbirth and birth in Brazil: an evolving scenario. Cad Saude Publica 2018; 34(5):e00063818.

13. Ceccon RF, Meneghel ST. Fascismo de gênero: controle, opressão e exclusão de mulheres. Rev Psicol Polit 2019; 19(46):449-458.

14. Oliveira BMC, Kubiak F. Racismo institucional e a saúde da mulher negra: uma análise da produção científica brasileira. Saude Debate 2019; 43(122):939948.

15. Castellanos MEP, Baptista TWF, Ayres JR. Entrevista José Ricardo Ayres. Saude Soc 2018; 27(1):51-60.

16. Seffner F, Parker R. The waste of experience and precariousness of life: contemporary political moment of the Brazilian response to aids. Interface (Botucatu) 2016; 20(57):293-304.

17. Minayo MCS. Violência: um velho-novo desafio para a atenção à saúde. Rev Bras Educ Med 2005; 29(1):5563.

18. Ordóñez-Vargas L. Gênero e Etnografia: reflexões desde algumas prisões brasileiras. Cad Pagu 2019; 55:e195508.

19. França AMB, Silva JMO. Maternidade em situação de prisão. Rev Baiana Enferm 2015; 29(4):411-420.
20. Sousa LMP, Matos INB, Paiva TRL, Gomes SM, Freitas CHSM. Regime of scarcity: food in the female penitentiary system. Cien Saude Colet 2020; 25(5):16671676.

21. Braga AGM, Angotti B. Da hipermaternidade à hipomaternidade no cárcere feminino brasileiro. Rev Int Direitos Human 2015; 12(22):229-239.

22. Kelsey CM, Medel N, Mullins C, Dallaire D, Forestell C. An examination of care practices of pregnant women incarcerated in jail facilities in the United States. Matern Child Health J 2017; 21(6):1260-1266.

23. Jardim D, Barbosa M, Modena CM. Obstetric violence in the daily routine of care and its characteristics. Rev Latino-Am Enferm 2018; 26:e3069.

24. Leal MC, Bittencourt SA, Esteves-Pereira AP, Ayres BVS, Silva LBRAA, Thomaz EBAF, Lamy ZC Nakamura-Pereira M, Torres JA, Gama SGN, Domingues RMSM, Vilela MEA. Avances en la asistencia al parto en Brasil: resultados preliminares de dos estudios evaluativos. Cad Saude Publica 2019; 35(7):e00223018.

25. Diniz SG, Salgado HO, Andrezzo HFA, Carvalho PGC, Carvalho PCA, Aguiar CA, Niy DY. Abuse and disrespect in childbirth care as a public health issue in Brazil: origins, definitions, impacts on maternal health, and proposals for its prevention. J Hum Growth Dev 2015; 25(3):377-384.

26. Shlafer RJ, Hardeman RR, Carlson EA. Reproductive justice for incarcerated mothers and advocacy for their infants and young children. Infant Ment Health J 2019; 40:725-741.

27. Brasil. Programa das Nações Unidas para o Desenvolvimento (PNUD). Programa de combate ao racismo institucional no Brasil [Internet]. Brasília; 2005 [acessado 13 abr 2013]. Disponível em: http://www.saude. sp.gov.br/resources/ses/perfil/profissional-da-saude/ grupo-tecnico-de-acoes-estrategicas-gtae/saude-da -populacao-negra/artigos-e-teses/boletim_eletronico_marabr_-_2005.pdf.

Artigo apresentado em 22/05/2020

Aprovado em 09/11/2020

Versão final apresentada em 11/11/2020

Editores-chefes: Romeu Gomes, Antônio Augusto Moura da Silva 